\title{
18
}

\section{Killing Two Birds with One Stone: Developing Northern Australian Adaptive Capabilities to Sustainably Develop Competent and Thriving Communities Capable of Responding Effectively to Natural Hazards}

Petra T. Buergelt, Douglas Paton, Andrew Campbell, Helen James and Alison Cottrell

\section{Introduction}

Northern Australia has the potential to become a powerhouse within Australia (Australian Government, 2015). However, as the same report pointed out, the realisation of this potential is threatened by Northern Australia's exposure to substantial natural hazards. These hazards include bushfires, cyclones and flooding as well as extreme heat and humidity for six months of the year. At the same time, the resources and capabilities required to mitigate the complex natural hazard risk are declining. Infrastructure issues that can be traced to how extreme weather and climatic conditions make construction and maintenance difficult and expensive. Social factors such as low population densities, communities of varying degrees of remoteness, low population diversity and population turnover compound to introduce other significant challenges to the human component of mitigation planning. Additional challenges arise 
in remote Indigenous communities from differences between Indigenous and non-Indigenous stakeholder views about how to interpret, reduce and respond to risks. These conditions have conspired to create circumstances in which even relatively large remote communities in Northern Australia have almost no formal emergency management capacity, and little spare capacity to fall back on when a hazard event occurs.

In this chapter, the above challenges provide the backdrop to understanding and exploring how to reduce and respond to the continuing and increasing risk natural hazard events present to the development of Northern Australia. This backdrop is also used to frame disaster risk reduction (DRR) capabilities (UNISDR, 2015) that can be used to sustainably develop adaptive and thriving communities capable of responding effectively to natural hazards. Utilising the work of Paton et al. (2014) and the holistic emergency management and capacity development model advanced by Buergelt and Paton (2014), we propose that integrating community development and disaster risk management that includes and utilises all sectors and levels of community approach would be the most effective pathway.

We start by describing how the substantial natural hazard risk in Northern Australia is a serious threat to developing this region. Next, we propose pathways for creating innovative solutions that facilitate developing Northern Australia. We deliberate how DRR strategies must collectively consider and address the social, economic and cultural challenges faced by communities, particularly remote Indigenous communities, across the region. From this discussion, an integrated, holistic and communitybased DRR framework emerges.

This framework shows how we could 'kill two birds with one stone'. The 'stone' is community development (Dalton et al., 2007). The first 'bird' derives from applying community development principles and practices to strengthen the everyday capacities and capabilities of communities. The second 'bird' emerges from recognition that the person, household and community capacities and capabilities developed by using community development strategies are fundamental to the development of sustained community-based DRR strategies (Paton et al., 2014; Paton \& McClure, 2013). Integrating community development and DRR in the manner envisaged offers a mechanism for reconciling the development of Northern Australia with the management of the natural hazards that have been identified as constraints on that development. We conclude 
this chapter by discussing the unique participatory research opportunities Northern Australia affords and the research needed to facilitate developing and implementing an integrated, holistic and community-based DRR and development framework.

\section{Northern Australia's Unique Context and Substantial Hazard Risks: A Serious Threat to Developing the North}

In Northern Australia, adaptive and thriving communities are a prerequisite to fulfilling the potential of the region to become a powerhouse within Australia (Australian Government, 2015) by ensuring societal, economic and environmental sustainability in the context of increasingly rapid change, uncertainty, insecurity and wicked problems (Cutter et al., 2015). ${ }^{1}$ In Northern Australia, the key contextual challenges to fulfil the region's potential include closing the gap between Indigenous and other Australians; ensuring education, employment and welfare outcomes; attracting and retaining people in regional economies reliant on volatile commodity markets; and food, energy and water insecurity (Garnett et al., 2009). However, the major challenge to realising this potential derives from Northern Australia’s unique hazardscape.

Northern Australia is dominated by substantial natural hazards. The natural hazards include bushfires, cyclones and flooding as well as extreme heat and humidity for six months of the year. Bushfires in the region burn, on average, $430,000 \mathrm{~km}^{2}$ (an area larger than Germany) every year and contribute nearly 50 per cent of regional greenhouse emissions (Murphy et al., 2015). If bushfires are not properly interacted with, they can have disastrous consequences for communities and ecosystems.

Besides its threat to human life, the ecological, household, infrastructure and societal costs associated with bushfires are enormous. In Australia, these costs average US $\$ 1.58$ billion per year (Mortimer et al., 2011). It is difficult to define specific costs in Northern Australia due to issues with record keeping (Allan \& Tschirner, 2009), but specific costs per property

\footnotetext{
1 'Wicked problems' are problems that are difficult to clearly define, complex due to the interaction of a large number of inter-related factors, constantly changing and requiring a transformation of mindset of a large number of people to be solved.
} 
have been estimated to reach $A \$ 420,000$. Additional social and economic costs can arise from short- and long-term bushfire-related evacuation and migration, and from loss of land, homes, livestock and critical community and business infrastructure (Commonwealth of Australia, 2012).

In addition to bushfires, Northern Australia's hazardscape is also characterised by moderate to high frequency cyclones, which affect Indigenous and non-Indigenous communities, particularly within $50 \mathrm{~km}$ of the coast (Commonwealth of Australia, 2012). Further, the widespread flooding that accompanies the monsoonal wet season disrupts lives and livelihoods in many communities, often for up to 90 days per year. Climate change will increase the frequency and intensity of these hazards, amplifying their potential destructiveness and making them more difficult to interact with (Department of Environment, 2015).

Northern Australia also has to confront the consequences of sea surface temperature increases. Temperatures in the Timor Sea are rising faster than almost any part of the world's oceans. Warming oceans and warmer air increase risk from possibly fewer but more destructive cyclones, with a higher proportion of Category 4 and 5 cyclones (CSIRO \& Bureau of Meteorology, 2014).

The impact of these cyclones is compounded by rising sea levels. Sea levels around Darwin have risen by $18 \mathrm{~cm}$ over the last 20 years, threatening coastal infrastructure and livelihoods of Indigenous communities dependent on formerly freshwater floodplain wetlands (CSIRO \& Bureau of Meteorology, 2014).

Climate change also adds threats from heat stress and vector-borne diseases (Department of Environment, 2015). It is estimated that monsoonal wet seasons will get wetter, and dry seasons longer and drier with the number of $35^{\circ} \mathrm{C}+$ days anticipated to rise from the current average of 11 to 60 days per year by 2030 (Bureau of Meteorology \& CSIRO, 2015). These climatic conditions will increase physical and mental health issues related to heat stress and potentially deter people from moving to or staying in Northern Australia. In addition, vector-borne diseases affecting both humans (e.g. mosquitos) and animals (e.g. ticks in cattle) will also increase. Individually and collectively, this increasingly hazardous environment will create significant risks to life, human health and wellbeing, economic productivity, infrastructure and ecosystems in 
Northern Australia. However, humans are also substantially contributing these natural processes becoming the kinds of events that represent the (hazardous) challenges introduced above.

While the process that ultimately underpins events societies label disasters are natural, the so-called 'natural disasters' are not 'natural' per se. Natural processes (e.g. fire and cyclones) become hazards only when they interact with people. These hazards, in turn, become disasters when the scale and consequences of hazard activity exceed the societal capacity to contain or respond to these natural processes.

Natural events only become disasters when two basic conditions are present. The first condition manifests when people decide to live in areas where natural hazards occur and to develop these areas by (e.g. building houses, infrastructure and businesses) in ways that are independent of their environment. That is, their decisions are based on exploiting the amenities and resources of an area, but do not consider the hazardous potential that arises from their societal development decisions. The need to consider this linkage introduces a social ecological dimension to understanding natural hazard risk and a need for more active considerations of the social contribution to this equation.

By choosing to live in an environment in which natural processes and resources offer people benefits and amenities, people also choose to live in an environment that can occasionally turn hazardous. To effectively coexist with this environmental dynamic, it is important that people and communities choose to accommodate both the beneficial and hazardous potential inherent within the environment. The latter can be facilitated by people and communities taking steps to reduce the likelihood of natural events turning into disasters by increasing their capacity to anticipate detrimental impacts and develop ways to adapt to and recover from periodic hazard consequences.

Developing adaptive capacities will become more important given that Northern Australia's hazardscape will become more challenging due to climate change processes. Thus, the second condition reflects the degree to which people and communities anticipate the consequences that could arise when extreme natural events occur and that these consequences could exceed their capacities to respond and act. Only if people and communities engage in this kind of environmental vigilance will they 
develop and implement the planning, mitigation and preparedness processes required to reduce their risk and to increase their capacity to cope, adapt and recover.

Consequently, to prevent or at least reduce losses to communities and ecosystems, it is crucial to improve environmental understanding and develop hazard mitigation and response strategies that focus on societal coexistence and the development of adaptive capabilities that increase the capacity of people and communities to proactively respond to social and environmental change and periodic natural hazard events. The cost effectiveness of these endeavours can be framed in terms of reducing costs (e.g. less disruption and quicker recovery) and increasing a multitude of co-benefits for residents and communities (e.g. creating novel approaches to ensuring that securing benefits from environmental engagement accommodates the mitigation of hazardous circumstances). However, given the complexity of social-environmental interactions, this will take some new ways of thinking and acting (see Pathways for Creating Innovative Solutions section below).

Reducing the risk of and responding to natural hazards is complicated by natural hazards being wicked problems that are characterised by a wealth of complex interconnected ecological relationships and interdependencies that are constantly evolving and changing (BNHCRC, 2013; Brown et al., 2010). Consequently, the development of new ways of thinking and acting must accommodate the ecological nature of development. The need for the latter was anticipated by Buergelt and Paton (2014) and Buergelt et al. (2017a) when they developed their ecological all-hazard interdisciplinary risk management and adaptation model (see Figures 18.1, 18.2 and 18.3). This work emphasises that it is paramount to identify, understand and interact holistically with the multitude of individual and contextual/environmental factors that affect ecological relationships for both development and DRR strategies. A need for this kind of holistic approach is acknowledged as being important for addressing the wicked challenges associated with anticipating, preparing for, responding to and recovering from natural hazard events (BNHCRC, 2013; Paton et al., 2015). 


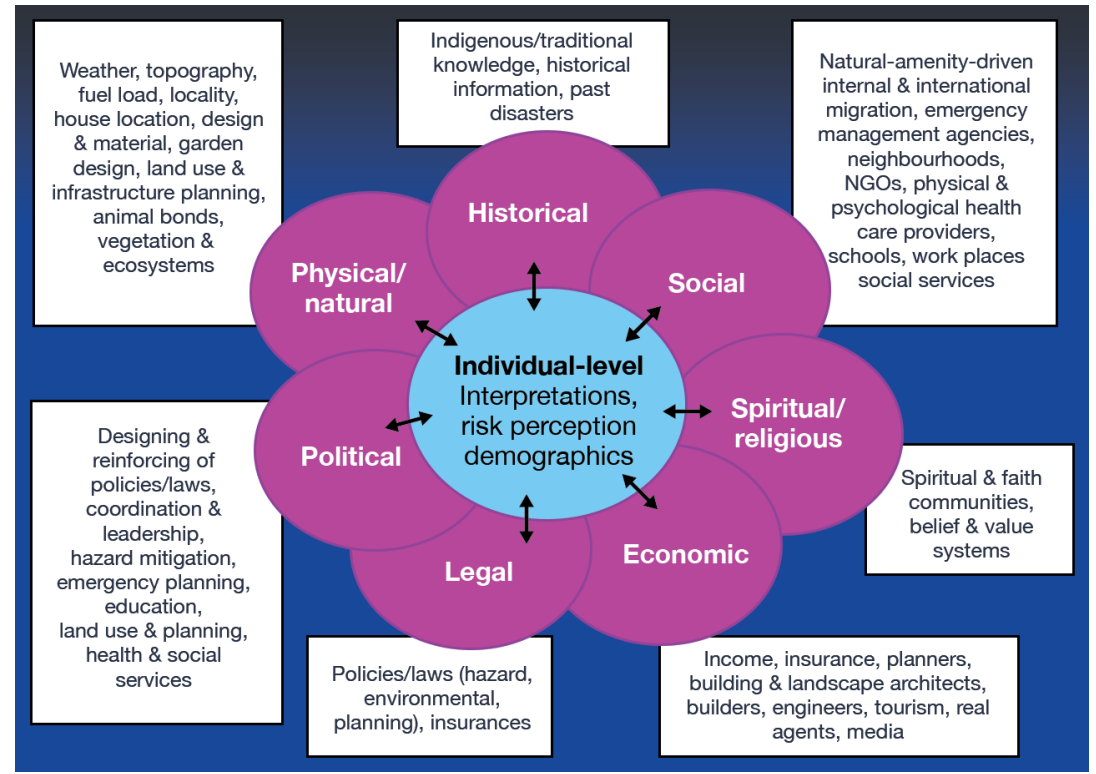

Figure 18.1: Ecological risk management and capacity building model: overview of community-level dimensions.

Source: Buergelt and Paton (2014).

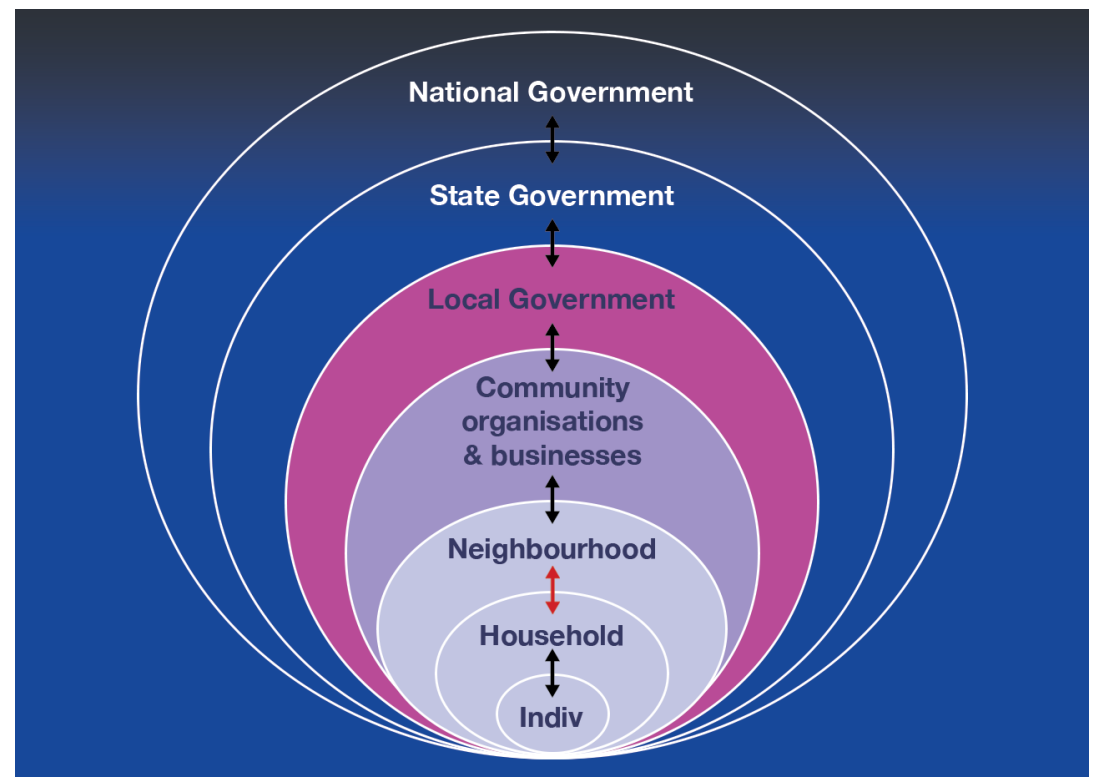

Figure 18.2: Ecological risk management and capacity building model: overview of community levels.

Source: Buergelt and Paton (2014). 


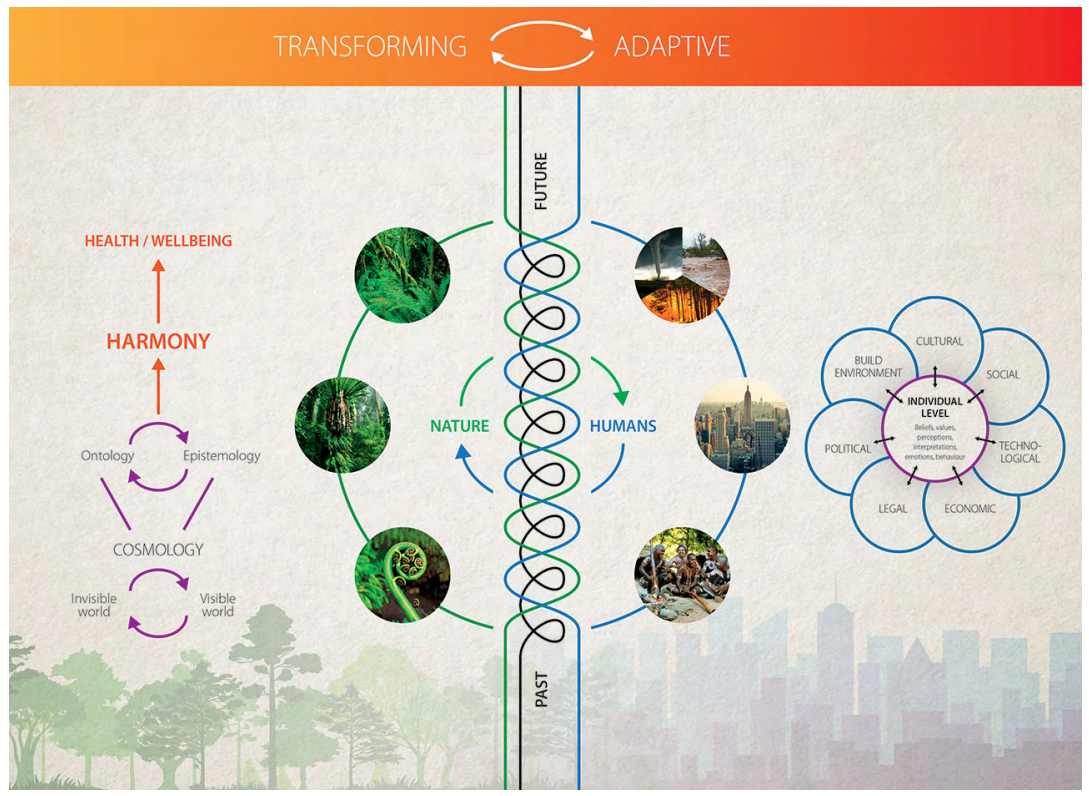

Figure 18.3: Revised risk management and capacity building model.

Source: Buergelt et al. (2017a).

At the same time, worldwide, it is becoming increasingly apparent that currently available resources and capabilities are increasingly inadequate for addressing the wicked challenges associated with anticipating, preparing for, responding to and recovering from natural hazard events (BNHCRC, 2013; Paton et al., 2015). In Australia, the predominant response to this issue has been framed in the national strategy for disaster resilience discussed in the National disaster resilience framework (Commonwealth of Australia, 2013). This report argued that developing community disaster resilience is crucial for effectively reducing the risk of natural hazards turning into disasters. The model outlined in Figures 18.1-18.3 provides a comprehensive overview of domains and how they interact over time that need to be considered when developing community disaster resilience. Consequently, realising the benefits of the national strategy will require strategies that consider and plan for accommodating and utilising, as far as possible, the domains described in Figure 18.1 at the different scales depicted in Figure 18.2. This is particularly important in the Northern Australian context. 
As outlined earlier, the development of community resilience throughout Northern Australia is complicated by infrastructure development and maintenance challenges. A resilience strategy must also accommodate weather and climate extremes and how they interact with a social environment characterised by population diversity and turnover, cultural diversity and communities of varying degrees of remoteness (some 360,000 people live in communities ranging from 'outer regional' to 'very remote', with an increasing proportion of Indigenous people living remotely). Cultural diversity introduces a need to accommodate the wide variety of views of Indigenous and non-Indigenous stakeholders about how to interpret, reduce and respond to hazard risks. The challenges inherent in this scenario are magnified by the remote geographical location of Northern Australian communities and the implications of this for the time and costs associated with assistance coming from other states due to colonising practices having undermined and continuing to erode the substantial adaptive individual and collective capacities Indigenous peoples and communities developed over millennia (Ali et al., 2021; Buergelt et al., 2017a).

In sum, the substantial natural hazard risk in Northern Australia poses a serious threat to realising the potential of the region to become the powerhouse that Australia's government envisages (Australian Government, 2015). At the same time, the unique social and environmental conditions prevailing in Northern Australia introduce several challenges to the task of developing the community disaster resilience required to reduce the threat by reducing the risk of extreme natural events and responding effectively to them when they occur (Commonwealth of Australia, 2013). In addition to their acting to constrain the development of resilience in Northern Australia, these conditions combine to impede developing the north's strategically important national and international role as Australia's base for responding to major natural hazards (bushfires, cyclones, tsunamis, earthquakes, volcanic eruptions), pandemics and terrorist attacks that occur elsewhere in the world (Commonwealth of Australia, 2012).

However, the significance of the issues that constrain the development of Northern Australia is amplified by focusing predominantly on the hazardous environmental factors and not pay adequate attention to the human and social factors that influence the likelihood of natural events turning into disasters. Yet, focusing on the human and social factors makes it is possible to argue, as we do here, that it is precisely the substantial, continuous and increasing threat of natural disasters that could be used to 
act as a catalyst for the development of the north. In the next section, we discuss how hazard events could act as catalysts by enhancing the day-today capacities of people and communities. We outline pathways we believe would facilitate developing Northern Australia in ways that reconcile the substantial natural hazard threats with continued, sustained development of individual and collective adaptive capacities.

\section{Pathways for Creating Innovative Solutions that Facilitate Developing Northern Australia}

We propose that the challenges posed by a complex and dynamic hazardscape to developing Northern Australia can be attributed, at least in part, to the fact that current DRR approaches, which focus predominantly on managing the natural environmental contributions to risk (e.g. mitigation and traditional risk communication), have not been particularly successful (Paton \& McClure, 2013; UNISDR, 2015). Thus, more effective approaches require new ways of thinking and acting to reduce and respond to disaster risk that are capable of contributing to realising the significant strategic and economic potential Northern Australia holds. That conclusion echoes Einstein's ${ }^{2}$ contention that 'a new type of thinking is essential if mankind is to survive and move toward higher levels'. That is, problems cannot be solved with the same kind of thinking that created them, pointing to the need to transform people's mindsets to create the collective transformations required to accomplish the desired outcomes. Individual and collective transformations must accommodate the complex and constantly changing ecological dialogical interactions pointed out by Buergelt and Paton (2014) and Buergelt et al. (2017a) in their ecological all-hazard interdisciplinary risk management and adaptation model (see Figures 18.1-19.3).

2 'The real problem is in the hearts of men' [Michael Amrine interview with Einstein] (1946, 23 June), New York Times Magazine as quoted in Icarusfalling (2009, 24 June), Einstein enigmatic quote [Blog post]. Retrieved from icarus-falling.blogspot.com.au/2009/06/einstein-enigma.html. 


\section{Developing Transformed Ways of Thinking and Acting}

The first shift in mindset involves facing and accepting the reality that hazard events are inevitable, can happen to us and are likely to become more frequent and severe in future. It also involves accepting the fact that while the activity of natural processes is inevitable, people can do much to reduce and respond to the nature and implications of the consequences hazard activity has for themselves and others. Accepting this reality would be facilitated by developing a mindset that focuses on coexisting with environmental benefits and the challenges and threats posed by natural environmental processes. A corollary of this is that any disaster that does occur can act as a catalyst for development. This potential is embodied in Sendai's call (UNISDR, 2015) to include the 'Build Back Better' concept in disaster recovery planning (Paton \& James, 2016). To fulfil this potential, it is necessary to fundamentally shift what people and communities think and do in their everyday lives prior to hazard events occurring.

Berkes et al. (2003) specified the mindset required. They argued that communities can more readily cope with and adapt to complex, dynamic and rapid change and challenges if the majority of people in communities are able to learn fast, understand complexity, synthesise seemingly separate pockets of knowledge and apply this new knowledge to continuously create and implement innovative solutions. From a DRR perspective, this introduces a need to focus on community development and change processes in DRR planning (Paton et al., 2014). A consequence of this approach is that DRR becomes fundamentally a community development activity that is complemented by risk management, rather than one that focuses on managing hazard processes directly or indirectly via reliance on, for example, hazard-focused risk communication processes. It is this latter shift, and one that focuses on creating adaptive transformative communities, that offers the potential for the complex Northern Australian hazardscape to become a catalyst for social and economic development.

According to Berkes et al. (2003), developing the mindset required to plan for and realise this potential necessitates dissolving barriers to learning; building on the substantial and diverse existing local knowledges and experiences; learning from experience of what worked, did not work and might work; synthesising diverse knowledges; focusing on high-level 
analyses; engaging in critical thinking; and imagining different scenarios from business as usual. However, the key to success in twenty-firstcentury societies will not only require the knowledge of how to effectively navigate through rapid change but the knowledge of how to effectively lead people and groups through change and pass that knowledge on to others to facilitate the evolution of change (Berkes et al., 2003). Pivotal to successfully conceptualising and enacting such ideas requires more comprehensive interdisciplinary perspectives and thinking.

Buergelt and Paton's (2014) ecological all-hazard interdisciplinary risk management and adaptation model (see Figures 18.1-18.3) offers a framework for the development of an interdisciplinary perspective. In accordance with this model, Buergelt and Smith (2015) argued that to thrive in the face of uncertainty due to environmental risk from bushfires, cyclones, flooding and heat (threat) and to create safe, sustainable and thriving communities (possibility) it is necessary to facilitate residents developing matching diverse physical, mental, emotional, social, cultural and spiritual capabilities. The challenge is to identify how to best create and facilitate individual and societal transformations that create the required mindsets in practice. The sense of shared fate and common purpose that can be engendered by the threat of natural hazards and by the possibility of developing a thriving Northern Australia could provide an ideal context for creating the willingness and openness to engage in transformative education (Paton et al., 2014).

Traditional informative education programs have proven to be ineffective in facilitating the required capabilities (Lindell et al., 2009). In contrast, innovative transformative education technologies such as transformative education, experiential learning, collaborative learning, neurolinguistic programming and scenario planning are capable of dissolving old ways of being and thinking that proved unproductive and creating the required new ways of being and thinking (DePoerter, 1992; Andreas \& Faulkner, 1996; Mezirow, 1996; DePoerter \& Hernacki, 1998; Smith, 1998; DePoerter et al., 1999; O'Sullivan et al., 2002; Cranton, 2006; Beard \& Wilson, 2006; O’Connor \& Seymour, 2011; Rose, 2011; Zaffron \& Logan, 2011). Transformative education facilitates people reconstructing the interpretations or meanings they assign to their experiences, resulting in ontological and epistemological transformations or shifts that motivate actions that are more adaptive (Mezirow, 1996; O’Sullivan et al., 2002). 
The holistic approach advocated above (Figures 18.1-18.3) means that there is urgent need for holistic systemic transformations in all components. This view is echoed by Berkes et al. (2003). Given that contextual components are the result of groups of people acting together and interacting with other groups within communities (e.g. governments, NGOs and businesses), systemic transformation requires transformations at the organisational and community level. Integrating community development and disaster risk management could facilitate the required systemic transformation. The threat of natural hazards to developing Northern Australia could be utilised to create the impetus for systemic shifts.

Transformative education pedagogies facilitate people seeing reality more clearly and actively facing it (Mezirow, 1996; O'Sullivan et al., 2002). Hence, transformative education holds the potential of people and communities to be able to see, accept and be with the complexity and uncertainty inherent in natural processes. This shift would enable people and communities to anticipate what they might have to contend with. This knowledge would inspire people and communities to seek, develop and implement solutions capable of adapting to the challenges identified. The key to adaptation is effective and efficient everyday competencies and relationships within communities (Paton \& McClure, 2013). Accordingly, it is crucial to give community development a more prominent place in DRR and management than has hitherto been the case.

\section{Integrating Community Development and Disaster Risk Management to Sustainably Develop Thriving Communities and Reduce Disaster Risk}

One reason people and communities are generally failing to anticipate the significance of the natural hazard risk they face and/or their ability to take responsibility for reducing their risk has been the separation of risk management from other aspects of social policy and practice designed to develop communities (O’Keefe et al., 1976; Paton \& McClure, 2013). This separation derives from a focus of formal risk management on the hazard and its physical characteristics. This focus has two basic consequences. The first consequence is that people commonly fail to differentiate the cause (over which they have no control) from the consequences of hazard activity that they can influence (Paton \& McClure, 2013). Second, and following from the last point, a predominant focus of traditional risk management on advising people of physical hazard activity (and its magnitude, severity, 
etc.) and using this to frame the recommended actions required to prepare has resulted in neglecting the development of the interpretive social and psychological capacities required to, for example, realistically interpret risk and make decisions under uncertain conditions (Lindell et al., 2009; Paton \& McClure, 2013).

As a result, traditional approaches fail to increase people's commitment to reducing risk and to developing their individual and collective capacities to reduce, adapt to and respond to extreme natural processes (Paton et al., 2014; Paton \& McClure, 2013). The cost of not developing individual and collective adaptive capacities is evident in the growing recognition of the important role these capacities play in how people collectively interpret risk and develop the capacities that enhance their ability to adapt to complex and rapid change (Norris, et al., 2008; Paton \& Johnston, 2006).

The national risk management approach discussed in the national disaster resilience framework suggests that developing community resilience also creates an access for reducing the risk of disasters (Commonwealth of Australia, 2013). The emphasis on community resilience provides a foundation for an approach that recognises that peoples' capacity to reduce and adapt to hazardous circumstances derives more from social capital developed from everyday personal and social experiences and interpretations, rather than from additional, specific risk management strategies. Hence, we go a step further and propose that the development of community resilience would be more successful and cost effective if we integrate community development and risk management strategies (Paton et al., 2014).

The focus of community development could change from seeking to encourage community support for reducing losses from hazard events to taking steps to safeguard and further enhance the everyday lifestyle, amenities and resources that attract people to the north by developing people's individual and collective capability to adapt (Norris et al., 2008; Paton et al., 2014). Buergelt and Paton's (2014) and Buergelt et al.'s (2017a) ecological all-hazard interdisciplinary risk management and adaptation model supports this approach, because it shows that all sectors of community are involved in and influence DRR (see Figures 18.1-18.3). 
In Northern Australia, integrating community development and managing disaster risk could include, for example, identifying and developing strength-based strategies that build on the intrinsic aspects that make Northern Australia an attractive place to live, work and play, while enhancing community capacity to respond effectively when the environmental processes that create these amenities turn hazardous. Strength-based strategies could include learning from people who have lived in Northern Australia for generations. Learning is especially useful from Indigenous people who have built up in-depth and holistic knowledge and developed strategies for effectively coexisting with natural hazards for millennia (Buergelt et al., 2017a). The strategies could also include relevant Indigenous and non-Indigenous leaders and organisations from various sectors truly working together with urban and remote communities long term to co-create sustained, novel processes and contexts that further enhance their capacities to adapt (Ali et al., 2021; Buergelt et al, 2017).

\section{Utilising Threat of Natural Hazards and Potential of Northern Australia as Catalysts for Transformation}

Reconciling how community development and DRR can be integrated requires people and society to do things differently. However, people dread change because it entails leaving the familiar and stepping into unfamiliar territory, can be challenging and offers the prospect of failing. Typically, only two conditions inspire change. First, crisis, or the threat of a crisis, propels people to change because crisis results in changes within the environment that render habitual ways of thinking and acting ineffective. An argument for pursuing this line of thinking derives from the Chinese symbol for crisis-it encompasses 'danger' and 'opportunity'. In Northern Australia, the key is combining both the threat and the possibilities to increase people's collective motivation to transform. This raises a question of how to create the kind of opportunity or desired outcome that can inspire people to change. One answer to this question may lie with facilitating transforming how people relate to their environment to focus on the need to safeguard against periodic hazardous circumstances if they are to sustainably avail themselves of the amenities and benefits afforded by the environment they live in. 
Such ways of thinking are possible. Chinese (and other Asian) environmental philosophies argued for relationships between people and environment to be based on principles of harmonious coexistence (Tianchen, 2003). While it is unrealistic to assume that the wholesale adoption of an environmental philosophy can be imported from one culture into another, the existence of beliefs and actions that facilitate the kind of environmental coexistence envisaged here does at least suggest that it is a goal worth pursuing (Buergelt et al., 2017a). To trigger the required transformations, however, will require something that will catalyse shifts in thinking. We propose that the Northern Australian hazardscape could be utilised as such a catalyst to facilitate the transformation required for the sustained development of adaptive, competent and thriving communities capable of more effectively responding to natural hazards.

While this pathway has not been attempted, the mechanisms that could be used to develop and implement this kind of change do exist. For example, the hazardscape could be used to create the kind of superordinate goal that can catalyse collective action (Paton \& Buergelt, 2012) using transformative pedagogies such as those highlighted above as a vehicle for transforming, reconciling and integrating stakeholder beliefs and practices. Because hazard effects are widespread, and involve and affect all sectors and levels of society, integrating community development and DRR offers the potential for whole-of-community efforts involving community, government, businesses, and researchers collaborating.

By encouraging all stakeholders (e.g. community members, communities and local and regional governments) to develop DRR approaches that focus on creating community capacity by utilising local individual and collective resources, disaster risk reduction and management become a subset of activities subsumed within environmental, cultural, social and economic community adaptive capacity building. This change in focus creates an opportunity to frame the Northern Australia hazardscape as a catalyst to inspire and lead holistic community development and social change. The shared challenges posed by natural hazards might propel people and communities to cooperate and collaborate. The threat also provides the urgency that focuses people to act. The threat could provide a useful context in which stakeholders can be identified, their respective views and interests elicited and transformed, and governance and planning processes that seek to accommodate diversity of views and interests developed to create high levels of cooperation and collaboration. 


\section{Developing Unprecedented Levels of Cooperation and Collaboration}

Because natural hazards do not respect human-made boundaries, unprecedented levels of cooperation and collaboration will be required among and between sectors across local, state, national and international levels to continually create and implement innovative responses as suggested by Buergelt and Paton's (2014) ecological risk management and capacity building model. This cooperation and collaboration will create cross-sectoral transformation, development and ownership of adaptive mindsets and actions and embed these adaptive capacities and responses into everyday community beliefs and practices.

At the coalface of community-based DRR, pre-existing networks can function as resources for the focus of community-based activities (e.g. professional, cultural, religious, sporting, environmental, artistic, women's and men's groups, schools and health services) (Buergelt \& Paton, 2014). According to Norris et al. (2008), resilience resides in four sets of interlinked, networked resources. Leadership is essential in creating these competencies. Often, such leadership comes from existing social networks operating both within and external to the community, which enable both intra- and inter-community resources to be activated. By empowering and linking the resources and leaderships of these groups, the adaptive capacity and competence of communities can be enhanced manifold (James \& Paton, 2016).

For this participatory civil society-based approach to be successful, the natural, human, man-made, cultural, social, spiritual, economic and political resources of local communities need to be able to operate at a high level of capability and competence (Buergelt \& Paton, 2014; Norris et al., 2008). However, people growing up in and living in individualistic cultures commonly do not develop the mindset and skills required for cooperating and collaborating. Moreover, governance structures developed by individualistic cultures can impede cooperating and collaborating. Hence, to respond effectively to natural hazards, people and communities need to further develop the mindset and skills necessary for collaborating. Communities also need to create governance structures that facilitate collaboration such as sociocracy (Buck \& Villines, 2007; 
Endenburg, 1998, 2002) and that explicitly consider risk and shape community expectations around responses to extreme events (Buergelt $\&$ Smith, 2015; Paton et al., 2015).

One feature of the Northern Australian social context currently defined as a limiting factor regarding collaboration and cooperation could be turned into a driver of cooperative action. This limiting factor is low population numbers and density, which means that more cultural, social, economic and religious/spiritual roles, including leadership roles, required for societal and community functioning are available than there are people to fill them and that organisations are under resource constraints (James $\&$ Paton, 2016). More roles and resource constraints can have both facilitating and limiting implications.

On the upside, more roles than there are people to fill these roles means there are more opportunities for people to step up and take up roles and to fulfil a variety of roles (Barker \& Gump, 1964; Bechtel \& Churchman, 2002). Further, people are used to taking on and being responsible for fulfilling roles. Both scenarios build capacities-they facilitate people making and having a wide variety of experiences and learning many new ways of thinking and acting within a short timeframe. Additionally, having to manage with limited resources creates the necessity for people to work together across organisations and sectors. Accordingly, they are more likely to have developed the mindset and skills necessary for working effectively in diverse teams.

On the downside, the same people being involved across a variety of roles increases the risk of them burning out. There may also be less diversity of views, reducing the capacity of communities to develop new views to create novel solutions and to anticipate alternative futures (Bechtel \& Churchman, 2002). This diminished capacity would make it more difficult to anticipate, plan for and respond to future events that may be more challenging than anything hitherto experienced, such as extreme natural hazards. Therefore, it is important to empower as many people as possible to become active participants in social civic life by taking up roles. People accepting the responsibilities of roles and effectively fulfilling roles can be facilitated using transformative education pedagogies.

Together, the outlined pathways create an integrated, holistic and community-based DRR framework that would enable people and communities to actively and continuously reduce, respond and adapt to 
extreme natural and potentially dangerous hazards. This capacity would facilitate developing Northern Australia. We now turn to a more detailed discussion of the benefits of this framework.

\section{Integrated, Holistic and Community- Based DRR Framework: Benefits}

The holistic, integrated and community-based DRR framework that emerged is being promoted as an effective means to enhance the capacity of people, communities and societies in disaster-prone areas to adapt and respond to natural hazards. The Hyogo Framework for Action (HFA) argued that adaptive capacities are a function of the capability of social systems to organise themselves in ways that increase its capacity for learning from past disasters, offering better future protection (UNISDR, 2007). Accordingly, as Paton and Johnston (2006, pp. 7-8) emphasised, natural hazard threats and disasters can be a 'catalyst for development opportunities'. This perspective is also supported by Thomalla and Schmuk (2004) and the IFRCRCS (2009). The latter highlighted the role DRR programs play in contributing to creating employment, building social capital and to developing a culture of hazard preparedness embedded in everyday community life. By facilitating and (re)activating local civil society capabilities inherent in Indigenous and non-Indigenous communities in both rural and urban areas, and creating conditions that enable them to collaborate and learn two-way effectively, the participatory approach to disaster governance can achieve several outcomes.

First, the integrated, community-based DRR framework described above enhances the reviving and redeveloping of capacities of local communities and values local worldviews, knowledges and practices (James \& Paton, 2016; Buergelt \& Paton, 2014). By identifying, activating, drawing out and reviving the resources and capacities inherent in Indigenous and nonIndigenous communities in rural and urban regions, and enabling diverse community members to effectively collaborate and learn two-way, the participatory approach to disaster governance not only draws out, and on, the resources and capacities inherent in the local communities, but also creates sociocultural, financial, health and environmental outcomes that create communities that attract and retain people. 
Second, local participatory governance is more likely to be effective in a long-term, sustainable way than top-down national-level approaches, which evaporate once the immediate crisis has passed. The role of the state or national governments is to provide an enabling policy framework for the implementation of participatory DRR governance. Third, this comparatively new approach to disaster governance can help to more effectively save lives and resources by embedding a culture of disaster preparedness in local communities (Mallick, 2014). Community-based DRR creates DRR as an ongoing process that is built into the community's everyday activities and improves quality of life in communities rather than being an additional task along with all the other tasks people and communities have to manage (see Paton et al., 2014, and James \& Paton, 2016, for examples).

Fourth, in the proposed framework groups traditionally perceived as vulnerable-especially Indigenous Australians, women, immigrants/ refugees and older people-are reframed as highly valuable resources due to having specific and sophisticated local, ecological, spiritual and cultural knowledge, experiences, perspectives and capabilities. As a result, these groups are included in community-based DRR and their input is highly valued, sought and harnessed.

Fifth, developing adaptive and thriving communities will also contribute to addressing the substantial attraction and retention issue Northern Australia is confronting by facilitating people becoming psychologically and socially attracted to the region and embedded into their communities (e.g. Norris et al., 2008; Paton et al., 2014; Paton \& McClure, 2013). Being attached to a place increases people's interactions in physical settings (Kyle et al., 2005) and creates the conditions necessary for the development of a sense of community (Tuan, 1977). The more people interact and feel they belong, the more they believe that members matter to one another and to the group, and that members' needs will be met through their commitment to be together (McMillan \& Chavis, 1986). The more people interact with each other, the more they care for each other. As a result, people are more interested in and motivated to take responsibility for improving their community and in getting actively involved in preparing for and responding to natural hazards because they want to protect the people they care for. Further, people are more committed to rebuilding their communities after natural hazards (e.g. Paton $\&$ McClure, 2013). These aspects are reinforcing each other, setting an upward spiral in motion. 
However, currently high population turnover, particularly in the Northern Territory (Australian Government, 2015; Roseman et al., Chapter 11, this volume), may be diluting these important aspects of social capital. Place attachment develops from people's perception of the capacity of a location to meet their personal and lifestyle goals (the amenity value of place) in ways consistent with their beliefs, feelings, values, goals and behaviours (place identity) (Norris et al., 2008). Consequently, strategies that increase the amenity value need to be identified and implemented to facilitate people more strongly identifying with and becoming attached to Northern Australia. People being attracted to and staying in Northern Australia is essential for creating the social capital that will contribute to community development and community-embedded DRR (e.g. James $\&$ Paton, 2016). At the same time, because high turnover has long been an issue in the north and is likely to continue, it might be worthwhile to start considering designing social learning systems that assume a high turnover (albeit with a stable population of long-term residents in many communities), rather than focusing only on reducing the level of turnover.

Assigning key roles to developing sense of community and place attachment provides a foundation for motivating the development of shared responsibility between all sectors of society to support the social capital-building activities organised around strengths-based DRR strategies (see Paton et al., 2014, for an example). Strategies that integrate risk management, community and economic development and poverty alleviation will play integral roles in fostering adaptation and transformation of at-risk communities (Norris et al., 2008).

\section{Northern Australia: Unique Participatory Research Opportunities and Needs}

Developing effective holistic, integrated, transformative and communitybased DRR in Northern Australia necessitates community-based participatory action research and evaluation. Northern Australia's unique urban, rural, environmental, social and cultural diversity creates ideal contexts for participatory hazard and recovery research. While large enough to encompass, for example, major social and societal aspects of urban life, social organisation and governance issues, the urban areas are small enough to conduct whole-of-community case studies. In addition, the social and cultural diversity due to high numbers of Indigenous 
peoples, national and international immigrants, fly-in/fly-outs and ruralurban mix provides a context for conducting research on major aspects of diversity.

In cities such as Darwin, the relatively high proportion of Indigenous residents creates a context not only for learning and understanding Indigenous hazard knowledge but comparing individualistic versus collectivist cultures. Darwin's proximity to Asia makes it an ideal location for researching cross-cultural similarities and differences, and international collaboration. This unique combination of valuable conditions creates a context for valuable comparative Indigenous and cross-cultural DRR research. While the relatively high population turnover in Darwin can create issues regarding key aspects of community resilience (such as diluting sense of community, place attachment and hazard knowledge), this same turnover provides unrivalled opportunities to shed light on social change processes over time.

The increase in natural hazards in Asia coupled with the proximity of Northern Australia to Asia also means that disaster and/or humanitarian aid (e.g. managing the influx of large numbers of dislocated people from Asia due to natural hazards or pandemics) is likely and that related scenarios can be simulated. Natural hazards in Northern Australia typically have an impact across state boundaries (Northern Territory and Queensland or Western Australia), requiring these states to work together across jurisdictional boundaries. Both aspects allow for creating and testing multi-state, national and international disaster and humanitarian aid collaboration.

Darwin and its surrounds do have human and social resources at least comparable to other Australian cities of similar size. The uncertainty stemming from the specific path and size of future cyclones being unpredictable creates a relatively uniform risk in the Darwin urban area (i.e. no one can say beforehand that they will definitely not be affected). This uniform risk is important for researching individual and collective DRR beliefs and behaviours. Additionally, emerging risk from bushfires around Darwin creates opportunities to investigate an emergent hazard and to further develop understanding of changes in DRR beliefs and action that need to be understood to proactively develop social capability to deal with climate change issues. 
Finally, but most importantly, Indigenous peoples and communities have historical, ecological, psychological, cultural, social and spiritual capacities that, if recognised, valued, listened to, revived and strengthened, would reduce the risk of extreme natural events occurring, and create adaptive and thriving Indigenous communities. Additionally, Indigenous worldviews, knowledges and practices also hold the key for creating adaptive and thriving communities in general (Ali et al., 2021; Buergelt et al., 2017a). Northern Australia provides unique and critical opportunities to build on existing relationships and knowledges of working with Indigenous communities to co-design, co-implement and co-evaluate Indigenist community-based participatory action research with Indigenous communities for the benefit of both Indigenous and Western peoples and societies (Ali et al., 2021; Buergelt et al., 2017b). These strong foundations could be used to create, together with Indigenous communities, effective community-based DRR approaches. This research would also contribute to finding and creating pathways towards addressing the 'gap' between Indigenous and nonIndigenous citizens (Commonwealth of Australia, 2012).

\section{Conclusion}

Taken together, utilising both the natural hazard threat and the possibility of Northern Australia to be Australia's powerhouse to motivate and implement a holistic, integrated and community-based participatory community development approach, based on Buergelt and Paton's (2014) ecological disaster management and capacity-building model, would facilitate developing Northern Australia effectively by killing two birds with one stone. First, this approach would contribute to the (re) development of adaptive, competent and thriving communities capable of utilising the unique opportunities Northern Australia offers and of fulfilling the potential critical national and international roles the Australian Commonwealth identified for Northern Australia. Second, this approach would reduce the likelihood of extreme natural events to occur and minimise the potential of them to turn into disasters, facilitating the development of Northern Australia. The suggested approach also points to value of community-based participatory action research approaches, especially those that are co-designed, co-implemented and co-evaluated. Finally, this approach creates many opportunities that answer the call of Australia’s BNHCRC (2013) to think in new ways and develop high- 
quality research, together with communities, that takes into account and addresses the needs of communities and the complex and interdependent nature of disaster dimensions and processes.

\section{References}

Ali, T., Buergelt, P. T., Maypilama, E. L., Paton, P., Smith, J., Yungirrna, D., Dhamarrandji, S., \& Gundjarranbuy, R. (2021). Facilitating sustainable disaster risk reduction in Indigenous communities: Reviving Indigenous worldviews, knowledge and practices through two-way partnering. International Journal of Environmental Research and Public Health, 18(3), 855. doi.org/10.3390/ijerph18030855

Allan, G. E. \& Tschirner, A. (2009). Pastoralists' perspectives on the costs of widespread fires in the pastoral lands of the southern Northern Territory region of central Australia, 2000-02. In G. P. Edwards \& G. E. Allan (Eds), Desert fire: Fire and regional land management in the arid landscapes of Australia (pp. 187208). Alice Springs, NT: Desert Knowledge Cooperative Research Centre.

Andreas, S. \& Faulkner, C. (1996). NLP: The new technology of achievement. New York, NY: William Morrow.

Australian Government. (2015). Our north, our future: White paper on developing Northern Australia. Retrieved from www.industry.gov.au/data-and-publications/ our-north-our-future-white-paper-on-developing-northern-australia

Barker, R. \& Gump, P. (1964). Big school, small school. Stanford, CA: Stanford University Press.

Beard, C. \& Wilson, J. P. (2006). Experiential learning: A best practice handbook for educators and trainers. London, England: Kogan Page.

Bechtel, R. B. \& Churchman, A. (2002). Ecological psychology. New York, NY: Wiley.

Berkes, F., Colding, J. \& Folke, C. (2003). Navigating social-ecological systems: Building resilience for complexity and change. Cambridge, England: Cambridge University Press.

Brown, V. A., Harris, J. A. \& Russell, J. Y. (Eds). (2010). Tackling wicked problems through the transdisciplinary imagination. London, England: Earthscan.

Buck, J. \& Villines, S. (2007). We the people: Consenting to a deeper democracy: A guide to sociocratic principles and methods. Washington, DC: Sociocracy Info. 
Buergelt, P. T., Maypilama, L. E., McPhee, J., Dhurrkay, G., Nirrpuranydji, S., Manyturrpuy, S., Wunungmurra, M., Skinner. T., Lowell, A., \& Moss, S. (2017b). Working together with remote Indigenous communities to facilitate adapting to using energy wisely: Barriers and enablers. Energy Procedia, 121, 262-269.

Buergelt, P. T. \& Paton, D. (2014). An ecological risk management and capacity building model. Human Ecology, 42, 591-603.

Buergelt, P. T., Paton, D., Sithole, B., Sangha, K., Campion, O. B. \& Campion, J. (2017a). Living in harmony with our environment: A paradigm shift. In D. Paton \& D. Johnston (Eds.), Disaster resilience: An integrated approach (2nd ed) (pp. 289-307). Springfield, Ill: Charles C. Thomas.

Buergelt, P. T. \& Smith, R. (2015). Wildfires: An Australian perspective. In D. Paton, P. T. Buergelt, S. McCaffrey \& F. Tedim (Eds), Wildfire hazards, risks and disasters (pp. 101-122). Hazards and Disasters series. London, England: Elsevier.

Bureau of Meteorology \& Commonwealth Scientific and Industrial Research Organisation (CSIRO). (2015). About monsoonal north. Retrieved from www. climatechangeinaustralia.gov.au/en/impacts-and-adaptation/monsoonalnorth/ (site discontinued).

Bushfire and Natural Hazards Cooperative Research Centre (BNHCRC). (2013). Call for papers. Melbourne, Vic.: BNHCRC.

Commonwealth of Australia. (2012). Australian emergency management hub: Bushfire. Retrieved from knowledge.aidr.org.au/

Commonwealth of Australia. (2013). National disaster resilience framework. Retrieved from www.em.gov.au/Publications/Program\%20publications/Pages/ NationalDisasterResilienceFramework.aspx (site discontinued)

Cranton, P. (2006). Understanding and promoting transformative learning (2nd ed.). San Francisco, CA: Jossey Bass.

Commonwealth Scientific and Industrial Research Organisation (CSIRO) \& Bureau of Meteorology. (2014). State of the climate 2014. Canberra, ACT: Commonwealth of Australia.

Cutter, S. L., Irasema Alcántara-Ayala, A., Altan, O., Baker, D. N., Briceño, S., Gupta, H., ... Wu, G. (2015). Global risks: Pool knowledge to stem losses from disasters. Nature, 522, 277-279. doi.org/10.1038/522277a

Dalton, J. H., Elias, M. J. \& Wandersman, A. (2007). Community psychology: Linking individuals and communities (2nd ed.). Belmont, CA: Wadsworth. 
Department of Environment. (2015). Climate change impacts in the Northern Territory.

DePoerter, B. (1992). Quantum learning: Unleashing the genius in you. New York, NY: Dell.

DePoerter, B. \& Hernacki, M. (1998). Quantum learning in business: How to be more confident, effective and successful at work. London, England: Piatkus Books.

DePoerter, B., Reardon, M. \& Singer-Nourie, S. (1999). Quantum teaching: Orchestrating student success. London, England: Allyn and Bacon.

Endenburg, G. (1998). Sociocracy as social design. Delft, The Netherlands: Eburon Academic Publishers.

Endenburg, G. (2002). Sociocracy: The organisation of decision-making. Delft, The Netherlands: Eburon Academic Publishers.

Garnett, S. T., Sithole, B., Whitehead, P. J., Burgess, C. P., Johnston, F. H. \& Lea, T. (2009). Healthy country, healthy people: Policy implications of links between Indigenous human health and environmental condition in Tropical Australia. Australian Journal of Public Administration, 68(1), 53-66.

International Federation of Red Cross and Red Crescent Societies (IFRCRCS). (2009). Early warning, early action. Geneva, Switzerland: IFRCRCS.

James, H. \& Paton, D. (2016). The consequences of Asian disasters: Demographic, planning and policy implications. Springfield, IL: Charles C. Thomas.

Kyle, G., Graefe, A. \& Manning, R. (2005). Testing the dimensionality of place attachment in recreational settings. Environment and Behavior, 37, 153-177.

Lindell, M. K., Arlikatti, S. \& Prater, C. S. (2009). Why people do what they do to protect against earthquake risk: Perceptions of hazard adjustment attributes. Risk Analysis, 29(8), 1072-1088.

Mallick, B. (2014). Cyclone shelters and their locational suitability: An empirical analysis from coastal Bangladesh. Disasters, 38(3), 654-671.

McMillan, D. W. \& Chavis, D. M. (1986). Sense of community: A definition and theory. Journal of Community Psychology, 14(1), 6-23.

Mezirow, J. (1996). Contemporary paradigms of learning. Adult Education Quarterly, 50, 5-23.

Mortimer, E., Bergin, A. \& Carter, R. (2011). Sharing risk: Financing Australia's disaster resilience (Australian Strategic Policy Institute, Special Report Issue 37). 
Murphy, B., Edwards, A., Meyer, C. P. \& Russell-Smith, J. (2015). Carbon accounting and savanna fire management. Melbourne, Vic.: CSIRO Publishing.

Norris, F., Stevens, S., Pfefferbaum, B., Wyche, K. \& Pfefferbaum, R. (2008). Community resilience as a metaphor, theory, set of capacities, and strategy for disaster readiness. American Journal of Community Psychology, 41(1-2), 127-150.

O'Connor, J. \& Seymour, J. (2011). Introducing NLP: Psychological skills for understanding and influencing people (Neuro-Linguistic Programming). San Francisco, CA: Conari Press.

O'Keefe, P., Westgate, K. \& Wisner, B. (1976). Taking the naturalness out of natural disasters. Nature, 260, 566-567.

O'Sullivan, E., Morrell, A. \& O'Connor, M. A. (Eds). (2002). Expanding the boundaries of transformative learning: Essays on theory and practice. New York, NY: Palgrave.

Paton, D. (2014). Disaster management for community workers. Taipei, Taiwan: Ministry of Health and Welfare.

Paton, D. \& Buergelt, P. T. (2012). Community engagement and wildfire preparedness: The influence of community diversity. In D. Paton \& F. Tedim (Eds), Wildfire and community: Facilitating preparedness and resilience (pp. 241259). Springfield, IL: Charles C. Thomas.

Paton, D. \& James, H. (2016). Identifying new directions in post-disaster livelihood, resilience and sustainability in Asia. In H. James \& D. Paton (Eds), The consequences of disasters: Demographic, planning and policy implications (pp. 357-369). Springfield, IL, Charles C. Thomas.

Paton, D. \& Johnston, D. (2006). Disaster resilience: An integrated approach. Springfield, IL: Charles C Thomas.

Paton, D. \& McClure, J. (2013). Preparing for disaster: Building household and community capacity. Springfield, IL: Charles C. Thomas.

Paton, D., Buergelt, P. T., McCaffrey, S. \& Tedim, F. (Eds). (2015). Wildfire hazards, risks and disasters. Hazards and Disasters series. Oxford, England: Elsevier.

Paton, D., Johnston, D., Mamula-Seadon, L. \& Kenney, C. M. (2014). Recovery and development: Perspectives from New Zealand and Australia. In N. Kapucu \& K. T. Liou (Eds), Disaster \& development: Examining global issues and cases (pp. 255-272). New York, NY: Springer. 
Rose, C. (2011). Accelerated learning for the 21st century: The six-step plan to unlock your master-mind. New York, NY: Random House.

Smith, A. (1998). Accelerated learning in practice. New York, NY: Continuum.

Tianchen, L. (2003). Confucian ethics and the environment. Culture Mandala: The Bulletin of the Centre for East-West Cultural and Economic Studies, 6(1).

Thomalla, F. \& Schmuk, H. (2004). We all knew that a cyclone was coming: Disaster preparedness and the Cyclone of 1999 in Orissa, India. Disasters, 28(4), 373-387.

Tuan, Y. F. (1977). Space and place: The perspective of experience. Minneapolis, MN: University of Minnesota Press.

United Nations International Strategy for Disaster Reduction (UNISDR). (2007). The Hyogo Framework for Action (HFA) 2005-2015: Building the resilience of nations and communities to disasters (UN Document A/CONF.206/6).

United Nations International Strategy for Disaster Reduction (UNISDR). (2015). Sendai framework for disaster risk reduction. Geneva, Switzerland: UNISDR. Retrieved from www.undrr.org/implementing-sendai-framework/ what-sendai-framework

Zaffron, S. \& Logan, D. (2011). The three laws of performance: Rewriting the future of your organisation and your life. Hoboken, NJ: Jossey-Bass. 
This text is taken from Leading from the North: Rethinking Northern Australia Development, edited by Ruth Wallace, Sharon Harwood, Rolf Gerritsen, Bruce Prideaux, Tom Brewer, Linda Rosenman and Allan Dale, published 2021 by ANU Press, The Australian National University, Canberra, Australia. 